\title{
Marcadores Territoriais da Fé Popular em Ponta Grossa: resistência social e cultural
}

\author{
Territorial Markers of Popular Faith in Ponta Grossa: social and cultural resistance
}

\author{
Marcadores Territoriales de la Fe Popular en Ponta Grossa: resistencia social y \\ cultural
}

\author{
Maximillian Ferreira Clarindo ${ }^{1}$ \\ https://orcid.org/ 0000-0003-2572-8789 \\ Nicolas Floriani \\ https://orcid.org/0000-0003-1629-3218
}

\begin{abstract}
RESUMO: Este artigo tem por objetivo geral discutir os marcadores territoriais e geossímbolos da fé popular que subsistem em meio às modernidades múltiplas do espaço urbano de Ponta Grossa. Os municípios do Paraná Tradicional possuem suas histórias atreladas à expropriação de terras indígenas com a escravização dos nativos e de negros trazidos do continente africano, na consolidação de atividades econômicas ligadas à agropecuária. Hoje, percebe-se que a sociedade local resgata para o quotidiano moderno algumas características de suas origens no sentir-pensarconstruir a cidade. Mesmo sendo Ponta Grossa a quarta maior cidade do Estado do Paraná, portanto com considerável grau de urbanização e modernidade, são preservados pela comunidade alguns marcadores territoriais que remetem a uma outra cidade, não perfeitamente alinhada às geoestruturas do capital. Entre olhos d'água, jazigos, santos canônicos e não canônicos, formata-se um corpus religioso-espiritual, dentro de uma relação secreta/emocional com o espaço. Inobstante, desde o método fenomenológico de análise, percebe-se que estes interditos espaciais personificam uma estratégia, mesmo que inconsciente, de resistência às imposições totalizantes da modernidade. Conclui-se, portanto, que os marcadores territoriais da fé popular descortinam a multiplicidade do urbano na medida em que ressignificam a modernidade por meio de outras racionalidades envolvidas na formatação espacial.
\end{abstract}

PALAVRAS-CHAVE: Fé popular. Marcadores territoriais. Microterritórios. Fenomenologia espacial.

\begin{abstract}
This article has as general objective to discuss the territorial and geosymbol markers of popular faith that subsist in the midst of the multiple modernities of the urban space of Ponta Grossa. The municipalities of Paraná Tradicional have their histories linked to the expropriation of indigenous lands with the enslavement of natives and of black people brought from the African continent, in the consolidation of economic activities related to agriculture. Today, it is perceived that local society rescues for modern everyday life some characteristics of its origins in the feel-think-build city. Even

\footnotetext{
${ }^{1}$ Doutor em Geografia pela Universidade Estadual de Ponta Grossa. E-mail: maxclarindo@hotmail.com.

2 Doutor em Meio Ambiente e Desenvolvimento (UFPR). Professor no Programa de Pós-Graduação em Geografia da Universidade Estadual de Ponta Grossa. E-mail: florianico@gmail.com.
} 
though Ponta Grossa is the 4th largest city in the State of Paraná, therefore, with a considerable degree of urbanization and modernity, some territorial markers are preserved by the community that refer to another city, which is not perfectly aligned with the geostructures of the capital. Between water strand, tombs, canonical and non-canonical saints, a religious-spiritual corpus is formed, within a secret/emotional relationship with space. Inobstant, from a phenomenological method, it is perceived that these spatials interdicts embody a strategy, even if unconscious, of resistance to the totalizing impositions of modernity. It is concluded, therefore, that the territorial markers of popular faith reveal the multiplicity of the urban in that they resignify modernity through other rationalities in spatial formatting.

KEYWORDS: Popular faith. Territorial markers. Microterritories. Spatial phenomenology.

RESUMEN: Este artículo tiene como objetivo general discutir los marcadores territoriales y geosímbolos de la fe popular que subsisten en medio de las múltiples modernidades del espacio urbano de Ponta Grossa. Los municipios de Paraná Tradicional tienen sus historias vinculadas a la expropiación de tierras indígenas con la esclavitud de nativos y negros traídos del continente africano, en la consolidación de actividades económicas relacionadas con la agricultura. Hoy en día, se percibe que la sociedad local rescata para la vida cotidiana moderna algunas características de sus orígenes en sentir, pensar y construir la ciudad. A pesar de que Ponta Grossa es la cuarta ciudad más grande del estado de Paraná, por lo tanto, con un grado considerable de urbanización y modernidad, algunos marcadores territoriales son preservados por la comunidad que se refieren a otra ciudad, que no está perfectamente alineada con las geoestructuras de lo capital. Entre fuentes de agua, tumbas, santos canónicos y no canónicos, se forma un corpus religioso/espiritual, dentro de una relación secreta/emocional con el espacio. Sin embargo, a partir del método fenomenológico, se percibe que estos interdictos espaciales encarnan una estrategia, aunque inconsciente, de resistencia a las imposiciones totalizadoras de la modernidad. Se concluye, por tanto, que los marcadores territoriales de la fe popular revelan la multiplicidad de lo urbano al resignificar la modernidad a través de otras racionalidades en la organización espacial.

PALABRAS-CLAVE: Fe popular. Marcadores territoriales. Microterritorios. Fenomenología espacial.

\section{INTRODUÇÃO}

Este artigo tem por objetivo discutir os marcadores territoriais e geossímbolos da fé popular que subsistem em meio às modernidades múltiplas do espaço urbano de Ponta Grossa. Os marcadores da fé popular atuam, seguramente, como fundamentos da cultura local, que resiste e adapta-se aos processos totalizantes de construção das espacialidades urbanas modernas hegemônicas, ressignificando-as ao produzir alternatividades à modernidade.

Em outros termos, buscar-se-á evidenciar a multiplicidade do território, sobretudo territórios culturais, a partir da composição de microterritorialidades híbridas organizadas no espaço urbano, que destoam do modo de produção capitalista. Fala-se, então, de outras emergências espaciais inseridas no urbano, assentadas nas entrelinhas produzidas pelas relações interpessoais daqueles que configuram as espacialidades, através dos processos de circular, trabalhar, permanecer e viver junto/coabitar (MATHIEU, 2010). 
Ao longo dos anos, Ponta Grossa assiste a processos modernizantes (que são estratégias globais), no entanto, a sociedade local não abdica de simbolismos e práticas sociais tradicionais regionais, colocando-se para além das imposições advindas das “instituições disciplinares" (FOUCAULT, 1999). Há, portanto, um processo dialético de resistência à cultura regional, revestida de práticas da medicina popular que tem uma origem rural, na construção das espacialidades urbanas, subvertendo a racionalidade instrumental e econômica imperativas do modo de viver e consumir o urbano hegemônico.

A releitura espacial proposta está acostada na interpretação fenomenológica e hermenêutica, isto é, pauta-se em uma Geografia humanística focada nas metaestruturas espaciais individuais (DI MÉO, 2014) que cada sujeito imprime através de suas vivências no processo organizacional espacial, interpretadas em termos paisagísticos e narrativos. As constatações aqui apresentadas são desdobramentos de pesquisas realizadas durante os anos de 2013 e 2019, interessadas em compreender a medicina popular praticada na região, na qual as benzedeiras da cidade atuam como verdadeiras guardiãs de saberes relacionados a este mote.

Durante esta caminhada, percebeu-se que em meio ao amálgama cosmo-míticoreligioso tradicional que formata os saberes e práticas da medicina popular havia uma série de outras relações com as espacialidades do entorno, tecidas pelas pessoas adeptas deste saber-fazer. Seja no meio rural ou urbano, algumas espacialidades são, então, ressignificadas por e para que a medicina popular seja perpetuada no imaginário individual e coletivo da região.

Inobstante, estas outras espacialidades são hiatos na vivência espacial cotidiana urbana, que se relacionam não só com saberes da medicina popular, mas também com a fé, com outros valores espirituais e ritualísticos, que eventualmente passam desapercebidos pela dinâmica do mundo em disparada como se refere Giddens (2002). Nelas há uma relação secreta/emocional que conecta diferentes pessoas pela dimensão do sagrado. Portanto, além dos marcadores territoriais representados pelas benzedeiras, constatam-se outros destinados ao socorro social, recheados de mitos e símbolos, e onde toda a sorte de pedidos e agradecimentos são executados, em um trânsito constante entre o sagrado e o profano, que recobra uma abordagem complexa de tais espacialidades.

Assim, metodologicamente, pautou-se em um caminhar geográfico prático, interessado em ver, ouvir e sentir as espacialidades, com foco a decifrar práticas e saberes inviabilizados/subjugados pelo logocentrismo. Trata-se, portanto, de uma pesquisa fenomenológica, pautada na observação. Considera-se que "O objeto de conhecimento para a Fenomenologia não é o sujeito nem o mundo, mas o mundo enquanto é vivido pelo sujeito". (GIL, 2008, p. 14). Ainda segundo o mesmo autor, "Assim, a pesquisa desenvolvida 
sob o enfoque fenomenológico procura resgatar os significados atribuídos pelos sujeitos ao objeto que está sendo estudado" (GIL, 2008, p. 15).

Parte-se para uma reflexão acerca da imaginação geográfica situada sob os alicerces do decolonizalismo científico, que pode suplantar o alcance limitado das explicações analíticas, descontextualizadoras e objetivantes do olhar disciplinar. Aborda-se o urbano, portanto, em uma perspectiva pluriversal, para além do "sistema-mundo" (ESCOBAR, 2014), transcendente às ontologias dualistas e homogeneidades na imaginação e sensação espacial, na medida em que os marcadores territoriais contribuem sobremaneira para o buen vivir (ACOSTA, 2016) social.

O buen vivir (Bem Viver) é um conceito relativamente recente. Trata-se de uma proposta de (re)pensar o processo de desenvolvimento da sociedade, sobretudo através do reencontro sociedade-natureza, suplantando a ideia monocultural, nas palavras de Acosta (2016, p. 33):

[...] o Bem Viver com sua proposta de harmonia com a Natureza, reciprocidade, relacionalidade, complementariedade e solidariedade entre os indivíduos e comunidades, com sua oposição ao conceito de acumulação perpétua, com seu regresso ao uso, o Bem Viver, enquanto ideia em construção, livre de preconceitos, abre as portas para formular visões alternativas de vida.

\section{COSMOVISÃO DA VIDA SOCIAL URBANA: MICROTERRITÓRIOS E MARCADORES TERRITORIAIS}

"O espaço urbano capitalista - fragmentado, articulado, reflexo, condicionante social, cheio de símbolos e campo de lutas - é um produto social, resultado de ações acumuladas através do tempo, e engendradas por agentes que produzem e consomem o espaço" (CORRÊA, 2004, p. 11).

A epígrafe que abre esta seção contempla uma definição de espaço urbano, dada por Lobato Corrêa, bastante completa. Hoje, o espaço urbano moderno é composto por vários microterritórios que se articulam entre si, de maneira negociada com territórios-globais (produtos do inacabado e incessante processo de globalização). "Os mesmos fatores que assim redundaram na exatidão e precisão minuciosa da forma de vida redundaram também em uma estrutura da mais alta impessoalidade; por outro lado, promoveram uma subjetividade altamente pessoal" (SIMMEL, 1973, p. 15).

A aposta para compreensão das múltiplas feições urbanas é aproximar a lupa sobre estes microterritórios, na tentativa de compreender seus símbolos e as lutas (em sentido lato) que neles e com eles são travadas diariamente. Fala-se de um espaço, cuja 
formatação escapa às lógicas cartesianas, mas inclina-se na projeção das subjetividades individuais, ou das metaestruturas espaciais individuais, como denomina Di Méo (2014).

Há que se aproximar das microhistórias e microgeografias que cada sujeito traz consigo quando constroem suas vidas e tecem relações sociais. Trata-se de sentir-pensar o território (ESCOBAR, 2014), além da disciplinarização e das instituições hegemônicas, interpretando-os enquanto revoluções moleculares, em alusão à conceituação de Félix Guattari (1987), na forma de habitar com e no espaço.

Em resumo, parte-se de um paradigma conjurado entre Geografia humanística e cultural, em que há o agenciamento pela ciência geográfica de diferentes saberes (científicos ou não), focado na compreensão da formação socioespacial desde uma análise das metaestruturas espaciais individuais. De acordo com Di Méo (2014), nesta tomada de ângulo:

Elas formam uma nova família de indicadores do funcionamento de uma instância ideológica. Levando em conta os escritos e a linguagem, o discurso dos habitantes, os monumentos e as memórias, as demonstrações, as cerimônias e as celebrações, as histórias e as obras de arte, os sinais e emblemas, os símbolos que escondem paisagens como espaço geográfico (etc.), todos esses elementos fornecem os marcos para uma instância ideológica intimamente associada à instância geográfica (DI MÉO, 2014, p. 49-50, tradução nossa).

O foco na instância ideológica ultrapassa a leitura espacial pautada unicamente pela hegemonia do capital. Destarte, se de um lado o capitalismo intenta balizar todas as práticas sociais, a ocupação urbana, na maioria dos casos, é condicionada ao capital - composição de geoestruturas (RAFFESTIN, 1986). Por outro, há exceções que escapam ao valor de troca, outras vivências espaciais que não atreladas diretamente aos ditames globais capitalistas.

\footnotetext{
$\mathrm{Na}$ medida em que as (micro)territorialidades constituem fragmentos organizados de sociação territorializada, elas podem ser capazes de concorrer para a refocagem da totalidade da cidade/metrópole. Essa capacidade investe as (micro)territorialidades de alguma "perigosidade" e rebeldia ao disputar as visões "globais", que são as visões hegemônicas institucionalizadas do mundo urbano. Permitem ver aquilo que vai sendo deliberadamente obscurecido e revelam mecanismos de produção da presença de muitos sujeitos e grupos subalternizados, assim como tornam audíveis discursividades indesejadas (FORTUNA, 2012, p. 202).
}

Pode-se dizer que estas outras vivências espaciais seriam também contra-estratégias (mesmo que não intencionais), quando a sociedade faz frente à reestruturação e controle do espaço pelo Estado e demais instituições interessadas neste processo, tais processos sendo passíveis de serem captadas por meio das "discursividades indesejadas". Alinhando- 
se à Simmel (1973) avalia-se que tais contra-estratégias são, outrossim, formas de autopreservação, e envolvem, inobstante, a instância da resistência cultural.

A presença das microterritorialidades relacionadas com a fé popular na cidade de Ponta Grossa ilustra elos de proteção individual e coletiva, arraigados à cultura local. São espacialidades que intermediam o (re)encontro da sociedade com a natureza, e as pessoas mantêm vívidas suas crenças, costumes, valores, rememoram seus antepassados e buscam suas raízes (múltiplas ruralidades); os efeitos da modernidade são mitigados e reprocessados em outras bases cognitivas.

Aborda-se, portanto, a trama de microterritorialidades interdependentes desde uma relação dialógica entre o moderno e o tradicional, que envolve tanto fluxos tangíveis como os não tangíveis. Trata-se de uma perspectiva transcendental e pouco explorada que reinterpreta as outras dimensões da expressão espacial, para além de uma perspectiva estruturalista. "Assim sendo, em cada elemento que estabelecemos como espacial já pensamos uma infinidade de direções possíveis, e é somente o conjunto destas direções que constitui o todo da percepção espacial" (CASSIRER, 2001, p. 54).

As múltiplas microterritoriedades existentes no espaço urbano moderno são também reflexos de múltiplas identidades nele entrelaçadas. Mesmo com a presença de diversos elementos de "desencaixe identitário" (empresas globais, outros idiomas, novas tecnologias, dentre outros), não há perfeito alinhamento entre as subjetividades modernas urbanas (o voraz consumidor do espaço), e as múltiplas subjetividades cotidianas assentes na diversidade de expressões do pensamento (científico, senso comum, religioso e artístico) que impulsionam diversas práticas, incluindo o agir espiritual e sagrado, muitas vezes secreto porque interdito. Desta maneira, há espaços urbanos em que o conjunto sensorial e as imagens mentais são processadas de maneira mais compassada (como se a vida acelerada e racionalmente organizada das cidades tivesse abertura para uma pausa).

Neste alinhamento, a cidade deve ser encarada com um complexo sistêmico, cuja complexidade se sustenta exatamente pela multiplicidade de vozes emudecidas pela ordem de unidade (FLORIANI et al., 2018). A partir desta complexa relação, a vida urbana possui outros sentidos, que podem ser observados pela presença de características sociais, como: o estreitamento de relações de vizinhança e estratégias de amortização de problemas sociais (circuitos locais de comercialização alternativa, a medicina popular com a presença de benzedeiras, remédios com ervas de quintais, relações de trocas etc.).

Em termos práticos, a modernidade não foi capaz de alterar o sentido de habitar (enraizamento, identificação e hábitos), nem mesmo suprimiu as bases míticas do devir urbano das cidades e da configuração socioespacial.

Bollnow (2008) aponta que há uma relutante concepção mítica do espaço, orientada por bases empíricas. É provável que a visão mítica da cosmogonia espacial seja reflexo do 
inconsciente coletivo, onde de acordo com Jung (2000) encontram-se as imagens primordiais e instintos da humanidade. Jung também argumenta que "Nossa mente consciente cria, continuamente, a ilusão de um mundo exterior "real", claramente definido, que bloqueia muitas outras percepções. No entanto, por meio da nossa natureza inconsciente conservamo-nos inexplicavelmente ligados ao nosso ambiente psíquico e físico" (JUNG, 2016, p. 277).

Neste devir, entre processos conscientes e inconscientes da produção-configuração do espaço urbano, encontram-se nestes microterritórios urbanos das cidades inúmeros marcadores territoriais, como se refere Silva (2010, p. 140), através dos quais a vida urbana possui distinta entonação.

Na sociedade urbano-industrial, esses "marcadores" podem ser percebidos, principalmente nas territorialidades do sagrado, em que as igrejas possuem fortes representações simbólicas e se mantêm vivas em razão de rituais, sendo essa estrutura rígida e decisivamente responsável pela conduta dos valores morais e espirituais. $\mathrm{Na}$ mesma direção, as necrópoles e monumentos possuem formas e representações semelhantes, todavia adquirem e acrescentam outros significados ao revelar o conteúdo e "status" social, econômico e político.

Deve-se considerar, no entanto, que as igrejas disputam as expressões sacras e o papel de balizadora de valores espirituais e morais com outros marcadores territoriais sustentados pela sociedade. As igrejas e cemitérios podem organizar ideias globais destes valores morais e espirituais, todavia as metaestruturas espaciais individuais revelam que, mesmo quando alguns marcadores se conectam às igrejas, há releituras destes valores.

A aparição das religiões universais e dos templos religiosos associam-se à aparição das cidades, de modo que "[...] a cidade e as profissões urbanas constituem as condições mais favoráveis à 'racionalização' e à 'moralização' das necessidades religiosas" (BOURDIEU, 2007, p. 84). Contudo, Bourdieu colaciona que, quanto maior for o grau de envolvimento urbano com tradições camponesas, maior será uma orientação da religiosidade popular para a magia, de modo que subsiste no meio urbano um sistema de crenças e práticas religiosas mais ou menos autônomo, que compete pelo monopólio dos "bens de salvação".

Nesta esteira, ao lado das igrejas, há outros marcadores territoriais que constituem expressão da fé popular e integram um complexo de saberes e práticas associados à cultura da cidade de Ponta Grossa e da região. Assim, deve-se avaliar que há valores religiosos e espirituais plurais em meio à sociedade, e muitas das vezes não são reconhecidos, quiçá intencionalmente, por não estarem amoldados aos dogmas institucionais.

A negação da presença de microterritórios é comum. É como se houvesse a necessidade de aprovação destes pelo poder dominante. Isto faz com que distintas 
apropriações espaciais, como as "cracolândias" - áreas de consumo de drogas -, os microterritórios de prostituição e os de comércio informal e ilegal, dentre outros, sejam espaços interditos, convivendo (junto de seus diferentes atores) como pano de fundo na sociedade.

Percebe-se empiricamente que os marcadores territoriais inseridos nos microterritórios urbanos e envolvidos com a fé popular congregam uma bagagem espacial ampla, quando encerram, por suas expressões no imaginário individual e coletivo, características que conferem valor cultural/social distinto. São características tanto fabricadas quanto historicamente posicionadas, cujo valor espiritual/religioso se torna apenas um dos elementos de uma ampla gama de vetores, posicionado ao lado da natureza, da presença de mitos e simbolismos diversos, de memórias, odores e sabores, dentre outros.

O olhar atento para o caminhar ordinário de pessoas comuns, com suas lutas e diferentes expressões afetivas, consolida a visão da pluriversidade espacial. Tal percepção é demonstrativa da riqueza complexa e diversa do sistema urbano, espaço geográfico ímpar, uno e múltiplo simultaneamente. Assim, as intencionalidades individuais culminam em uma distinta forma de habitar e de imaginar o espaço urbano, envolvendo o resgate de antigas práticas, saberes e valores combinado com uma incontinenti ressignificação de conteúdos modernos, típicos da vida urbana contemporânea.

As presentificações destes marcadores territoriais são reflexos de uma vida social assinalada por diferentes mitos e símbolos e que é fortemente orientada por forças espirituais e valores religiosos. Nos bairros de Ponta Grossa, esta cosmovisão confronta a ideia de que a vida urbana abdica de um pensar-agir emocional pela racionalização/objetivação das coisas do mundo. "Todos esses feitos são tão difíceis de explicar porque pertencem a um âmbito que se encontra ainda antes da formação de nossa consciência objetiva. [...]" (BOLLNOW, 2008, p. 322). Spivak (2010, p. 91) aponta que "Articular essa formação ideológica - medindo silêncios, se necessário - no objeto de investigação é parte do nosso projeto de "desaprendizagem". Neste endereçamento, adiante serão apresentados alguns marcadores territoriais relacionados com a fé popular que foram identificados no espaço urbano de Ponta Grossa, e que apontam para uma peculiar riqueza cultural da região.

\section{OS MARCADORES TERRITORIAIS DA FÉ POPULAR NA CIDADE DE PONTA GROSSA}

A cidade de Ponta Grossa, como boa parte dos municípios do Paraná Tradicional e do país, como um todo, tem uma origem atrelada à expropriação de terras e escravização de indígenas e também de pessoas negras trazidas do continente africano na organização e manutenção do trabalho agrícola. A região dos Campos Gerais, na qual Ponta Grossa é o 
núcleo, era rica em pastos naturais, o que a tornou um ponto estratégico para a parada e pernoite de tropas que se deslocavam pelo caminho do Viamão, entre Sorocaba/SP e Rio Grande do Sul no século XVIII (MELO; MORO; GUIMARÃES, 2007).

Assim, com o passar dos anos, ao redor dos pontos de pouso e descanso foi se consolidando uma sociedade campeira na região onde mais tarde se estruturaria o município de Ponta Grossa. A cidade durante sua história assistiu inúmeros conflitos envolvendo as elites campeiras que se organizavam com características militares na região (ZULIAN, 2009).

Ao longo dos anos, acompanhando as mudanças de cenário econômico nacional e mundial, essa sociedade rural foi se modernizando e se urbanizando, sobretudo pelo advento das estradas de ferro que começaram a cruzar a cidade. As ferrovias trouxeram inúmeros migrantes, especialmente europeus, para trabalhar na construção e depois na manutenção/operação na malha ferroviária (MONASTIRSKY, 2006).

Destarte, do ponto de vista étnico a sociedade ponta-grossense é plural, já que se estrutura através de bases indígenas, de negros e de povos europeus. A lógica da ocupação urbana da cidade guarda consigo também traços do passado campeiro, no qual se situa sua gênese. Neste viés, diferentes culturas se interconectam no urbano local, em um diálogo infinito entre modernidade e tradição.

Fala-se de uma complexidade histórica e geográfica envolvida com a consolidação do município, o que concita uma aproximação das subjetividades dos grupos sociais que a integram, tal qual recomenda Bonnemaison (2002). É nesta aproximação, em que são reveladas diferentes apropriações espaciais que ocorre a percepção de espacialidades cuja entonação é distinta dos processos hegemônicos urbanos-industriais.

Em Ponta Grossa, além da presença de diferentes hábitos sociais relacionados com a tradição do campo (hortas comunitárias, presença de alguns veículos de tração animal, diferentes geossimbolos rurais etc), há alguns referenciais espaciais que integram a medicina popular (tradição na região) e o corpus de valores espirituais e/ou religiosos. Tratam-se de marcadores não "oficiais" ou institucionais, que são apropriados pela sociedade que Ihes atribui significação distinta. São eles: os túmulos de Corina Portugal e de Dom Antônio Mazzarotto, a Gruta do Santa Mônica e o Olho d'Água São João Maria.

O jazigo de Corina Portugal, como ficou popularmente conhecida a jovem Corina Antonieta Portugal, localiza-se no Cemitério Municipal de Ponta Grossa (n. 0 1258). Corina nasceu na Cidade do Rio de Janeiro em 1869, onde conheceu, com apenas 15 anos de idade, o farmacêutico Alfredo Marques dos Campos. O namoro virou casamento, e após o matrimônio o casal migrou para Ponta Grossa, em busca de uma vida sossegada e financeiramente melhor. 
Foi em Ponta Grossa que o destino de Corina foi tragicamente selado. Em uma discussão com o marido em 1889, este a matou, desferindo 32 facadas. Alfredo, após o feminicídio fugiu para Minas Gerais onde mais tarde suicidou-se por não aguentar a pressão da opinião pública que havia descoberto seu assombroso crime nos Campos Gerais paranaense. Boatos da época apontavam que a razão da morte de Corina teria sido um suposto adultério cometido por ela. No entanto, não demorou até que o adultério fosse desmentido na sociedade, mesmo com a absolvição por unanimidade do autor e condenação dela própria por sua morte (FERNANDES, 1999).

Corina ganhou fama de Santa quando o prefeito Vicente Bittencourt mandou alguns de seus funcionários remanejar os cadáveres que estavam no antigo cemitério São João para a abertura da Avenida Vicente Machado (até hoje uma das principais da cidade). Ao escavar o túmulo onde estavam os restos mortais de Corina, o encontraram intacto, com a aparência de uma Santa. Os funcionários chamaram um padre para atestar o que encontraram. Quando o religioso chegou ao local pediu aos funcionários que guardassem segredo do que haviam visto (CARNEIRO JUNIOR, 2005).

O segredo não foi bem guardado e a notícia se espalhou. Hoje, seu túmulo recebe um número expressivo de visitantes (Figura 1), especialmente às segundas-feiras (considerado o dia das almas). Nele, há uma infinidade de agradecimentos por graças alcançadas, bilhetes com novos pedidos, flores etc. Corina é uma das "Santas de cemitério", como denomina Maués (2005).

Inobstante o seu cadáver preservado, outro fator preponderante para a elevação de Corina à condição de Santa Popular foi o fato de uma ponta-grossense que sofria violência doméstica ter procurado o túmulo para pedir a intercessão da Santa em sua vida conjugal. No dia seguinte, o seu marido mudou completamente seu comportamento: deixou o consumo de álcool e tornou-se um homem bom. A partir disso, várias mulheres com problemas conjugais e que sofrem violência doméstica buscam a sua ajuda (PETRUSKI, 2012). Desde 2010 funciona na cidade de Ponta Grossa a "Casa Corina Portugal", cujo endereço é sigiloso por questões de segurança, que se destina a acolher mulheres e filhos menores, vítimas de violência doméstica (Lei municipal $n$. ํ 10.219/10) (SILVA, 2016).

A santificação não oficial de pessoas comuns é uma lógica complexa. Petruski (2012) aponta que o reconhecimento de santos pela sociedade se dá em âmbito local, com múltiplos motivos, já que não há uma lógica delineada para tal. A autora acrescenta que o processo "[...] é uma condição "aberta" que pode ser atingida com base nos pontos estabelecidos pelos próprios devotos, pois são eles os responsáveis pela construção desse modelo de santidade" (PETRUSKI, 2012, p. 162).

Maués (2005) apõe que é comum nos cemitérios do Brasil a presença de Santos não canônicos. São "corpos santos", como se refere o autor, e seus jazigos, assim como ocorre 
no de Corina, recebem diversas homenagens por graças alcançadas e milagres concretizados. No caso de Corina, sua santificação, sob a ótica de Félix Coluccio (1995) está no grupo das vítimas de morte violenta ou injusta. Coluccio aponta que nesta categoria há um expressivo número de mulheres - aqui há uma discussão de gênero que merece ser mais bem explorada em outra oportunidade.

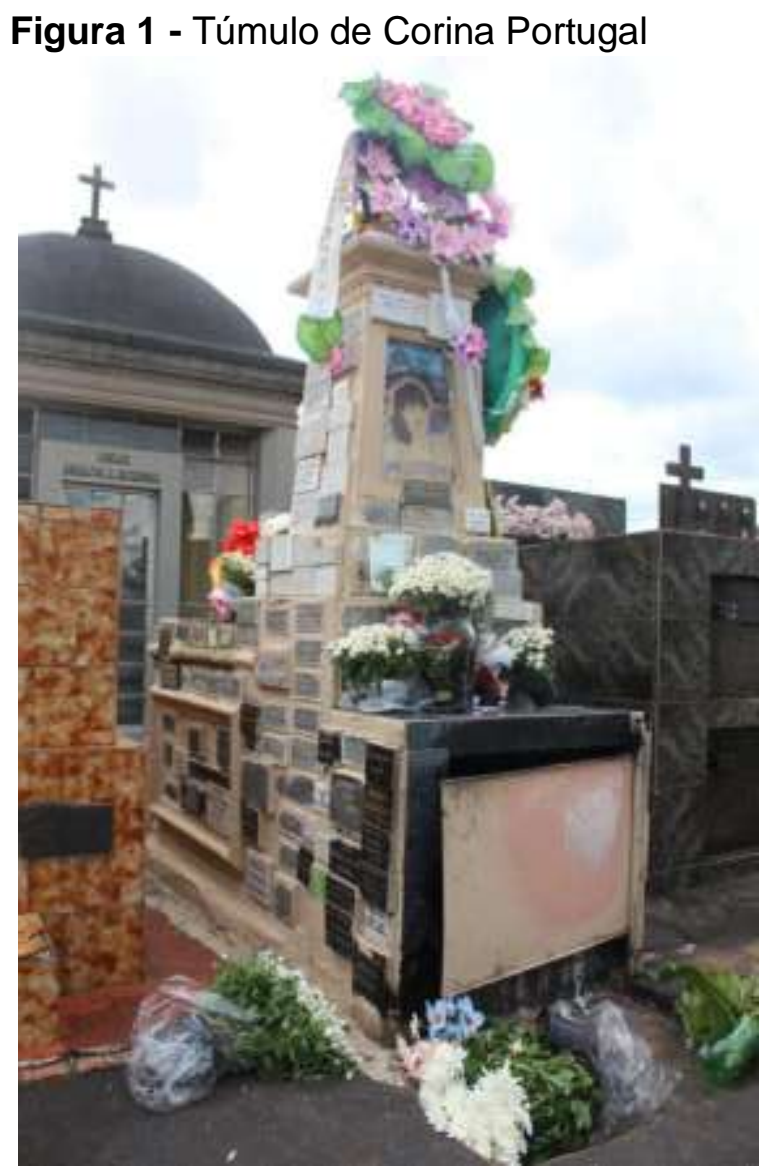

Fonte: Clarindo, 2019.

Ponta Grossa possui outro jazigo com características semelhantes ao de Corina Portugal, porém congrega uma releitura das santidades e da fé popular ainda mais complexa. O 1ำ bispo da cidade, Dom Antônio Mazzarotto, é considerado Santo por algumas pessoas da cidade. Seu túmulo (Figura 2) também recebe expressivo número de visitantes todos os dias no interior da igreja Sagrado Coração de Jesus, conhecida popularmente por "Igreja dos Polacos", no centro da cidade.

Dom Antônio Mazzarotto nasceu em 1ํ de setembro de 1890 em Santa Felicidade/PR, foi ordenado padre em 23 de novembro de 1914, aos 24 anos de idade, pelo Dom João Francisco Braga, 3ํ bispo da diocese de Curitiba. Comandou a Diocese de Ponta Grossa de 23 de fevereiro de 1930 até 24 de abril de 1965, quando teve seu pedido de renúncia aceito. O bispo morreu com 90 anos no dia 15 de julho de 1980, na cidade de Ponta Grossa. 
Figura 2 - Túmulo de Dom Antônio Mazzarotto



Fonte: Clarindo (2019).

A santificação não institucional de um Bispo cuja relação com a igreja é óbvia e reluzente, aponta para a complexidade dos santos não canônicos. D. Antônio tinha gosto pela escrita e todo dia 23 de fevereiro, no aniversário de sua ordenação, publicava uma carta pastoral, fato que perdurou durante toda sua atuação na cidade de Ponta Grossa, entre 1930 e 1965 (ZULIAN, 2009).

As cartas pastorais de D. Antônio, textos canônicos, objetivavam se comunicar com a comunidade católica de Ponta Grossa (clero e fieis). Com aparente inclinação catequética, as cartas exploravam conceitos da fé católica e pautavam-se na ideia de restauração do reino de Cristo na terra.

D. Antônio era bastante conservador e fiel aos dogmas da igreja católica. Seu conservadorismo e convicções ortodoxas o puseram em conflito com as novas diretrizes propostas pelo Papa João XXIII em 1962, no Concílio Vaticano II (também conhecido pela expressão em italiano: aggiornamento). As mudanças propostas para a igreja intentavam acompanhar o ciclo modernizante do mundo, propiciando uma abertura de diálogo e abdicação do posto de verdade absoluta na sociedade.

O Bispo ponta-grossense, diante da enorme reviravolta ocorrida na igreja após o Concílio Vaticano II, passou a ter dificuldades no diálogo institucional. D. Antônio Mazzarotto 
militava com afinco através de suas cartas e atitudes na manutenção da moral e bons costumes, estimulando seu clero a atuar da mesma maneira.

Sem razão formal explícita, com a última carta pastoral, em 1965 o bispo renunciou. Zulian (2009) considera que a causa provável da renúncia tenha sido um jogo político tramado nos bastidores da igreja, no qual ele não tivera participação, e tampouco consultado. É provável que a não aceitação da modernidade latente na igreja e na sociedade pesaram na sua deposição do cargo com sua substituição pelo Bispo Dom Geraldo Micheletto Pellanda.

Após a renúncia, D. Antônio recolheu-se em solidão, deixou de publicar seus escritos e não se expressou mais publicamente, somente atendia quem the procurasse para orientação espiritual. Dom Antônio fez "[...] esse não-dizer" ter sentido" (ZULIAN, 2009, p. 374).

Os motivos pelos quais o Bispo é considerado Santo por uma parcela da comunidade local não são evidentes. Talvez esta santificação ocorra por um estímulo do sentimento de compaixão pela forma com que se deu sua substituição, ou mesmo pelo fato de ter sido o primeiro Bispo da cidade. É provável também que sua postura rígida tenha agradado a elite campeira da época.

A cidade o aceitou ao longo do período de seu episcopado porque a sua proposta anticomunista, devocional, mariana, de estrita observância da ordem e de obediência à autoridade, especialmente à sua, era culturalmente aparentada do imaginário local, calcado sobre esses mesmos valores (ZULIAN, 2009, p. 383).

Há pessoas que visitam apenas o túmulo para suas preces, deixando de lado o contexto da igreja onde ele está depositado. Mas há também aqueles que passam pelo jazigo na entrada e depois seguem em oração/reza em reverência aos demais simbolismos presentes no pavilhão da igreja. Neste sentido, deve-se considerar que:

A pretensa unidade e organicidade conquistadas pela Igreja mascaram a multiplicidade de apropriações do catolicismo entre os próprios membros da instituição, ocultando uma variedade de compreensões e vivências da ortodoxia, de doutrina, de liturgia, técnicas, prédicas, cura de almas e uma grande diversidade de experiências religiosas. Essa multiplicidade pode ser estendida para os embates cotidianos, seja ele no interior dos movimentos e associações nas paróquias, na "leitura" das devoções por parte da população, na imprensa e outros órgãos de divulgação ou até mesmo nas múltiplas ocasiões de resistência às práticas reformadas. Pois os indivíduos sempre conseguem preservar espaços de liberdade, marcados muitas vezes pela transgressão e rebeldia, burlando o institucional, reinventando-o, e transitando por posições distintas, inclusive na esfera religiosa (ZULIAN, 2009, p. 57). 
Pensa-se que a devoção da população para com sua pessoa é parte integrante de um complexo cognitivo que margeia a crença, que burla o institucional (como Zulian se refere) e dá outra direção ao sensorial e ao espiritual. É uma releitura espacial e social das instituições, como se discutiu no tópico anterior.

Nesta esteira de ressignificações, a gruta existente na vila Santa Mônica (Figura 3) é outro marcador territorial que serve à fé popular das pessoas da região. Na gruta, construída sobre uma vertente d'água, era comum a realização de rezas e a reunião da comunidade para o exercício da fé e compartilhamento de suas experiências espirituais.

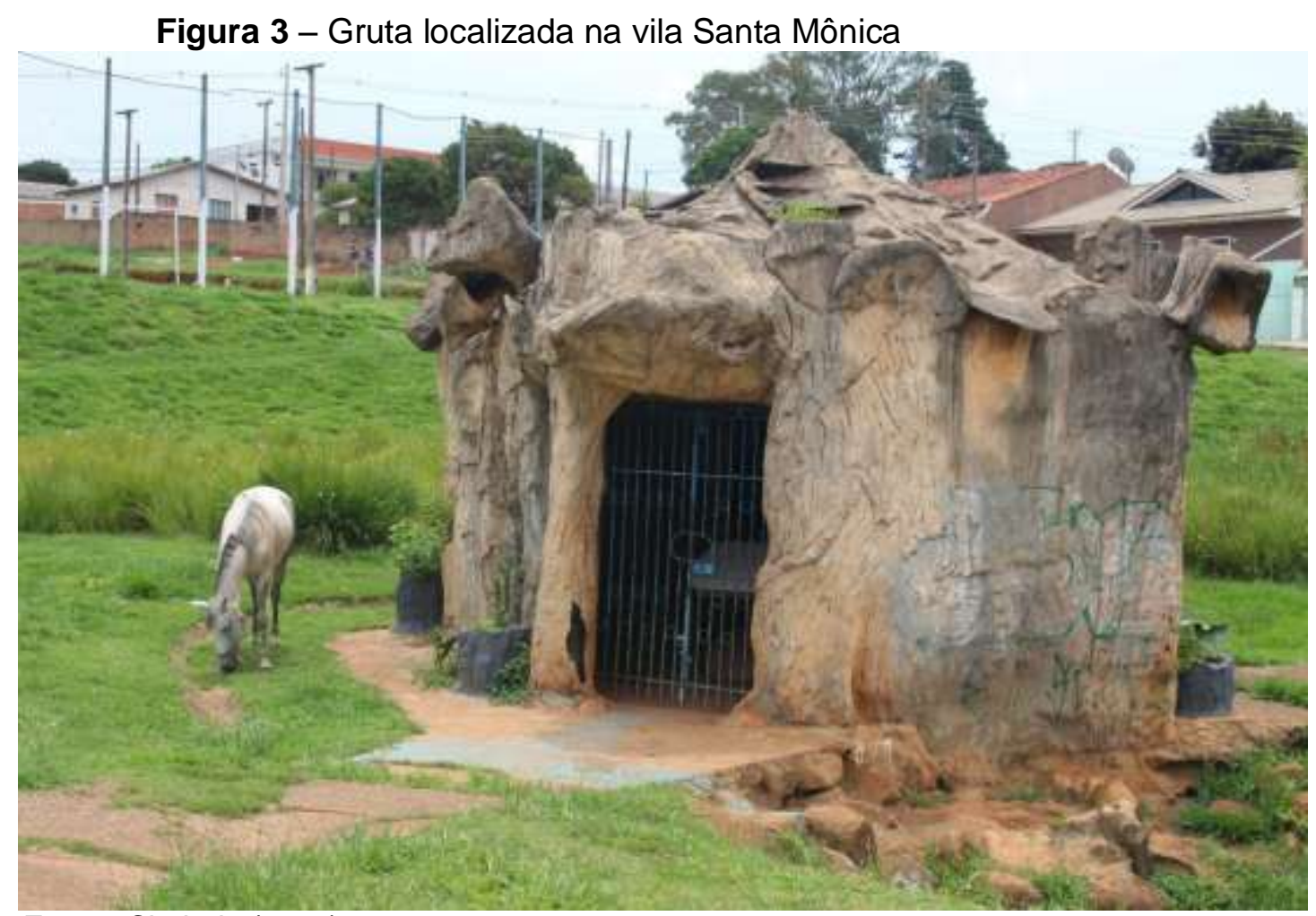

Fonte: Clarindo (2019).

O uso do pretérito se dá em face de que a gruta atualmente encontra-se aguardando uma revitalização. A obra de arte foi projetada pelo artista plástico Arno Felix Vaccari e construída pela Prefeitura Municipal em 2004 em uma das praças da vila. Nela há uma imagem grande de Santa Mônica (Figura 4), doada no passado pelos irmãos Maristas que moram nas proximidades.

A história aponta que o principal milagre atribuído à Santa Mônica é a conversão do próprio filho: Santo Agostinho. Durante 30 anos ela rogou pela conversão do filho. Sua presentificação se dá, portanto, especialmente para mães que buscam graças para os filhos.

A existência de um olho d'água na gruta representa a aproximação da crença popular com a natureza, através da atribuição de valor sagrado ao local. A hierofania (ELIADE, 
2000), é comum em vertentes de água espalhadas pelo país, e em várias delas há a crença de que a água que jorra possui característica curativa/protetiva.

Figura 4 - Imagem de Santa Mônica no interior da Gruta

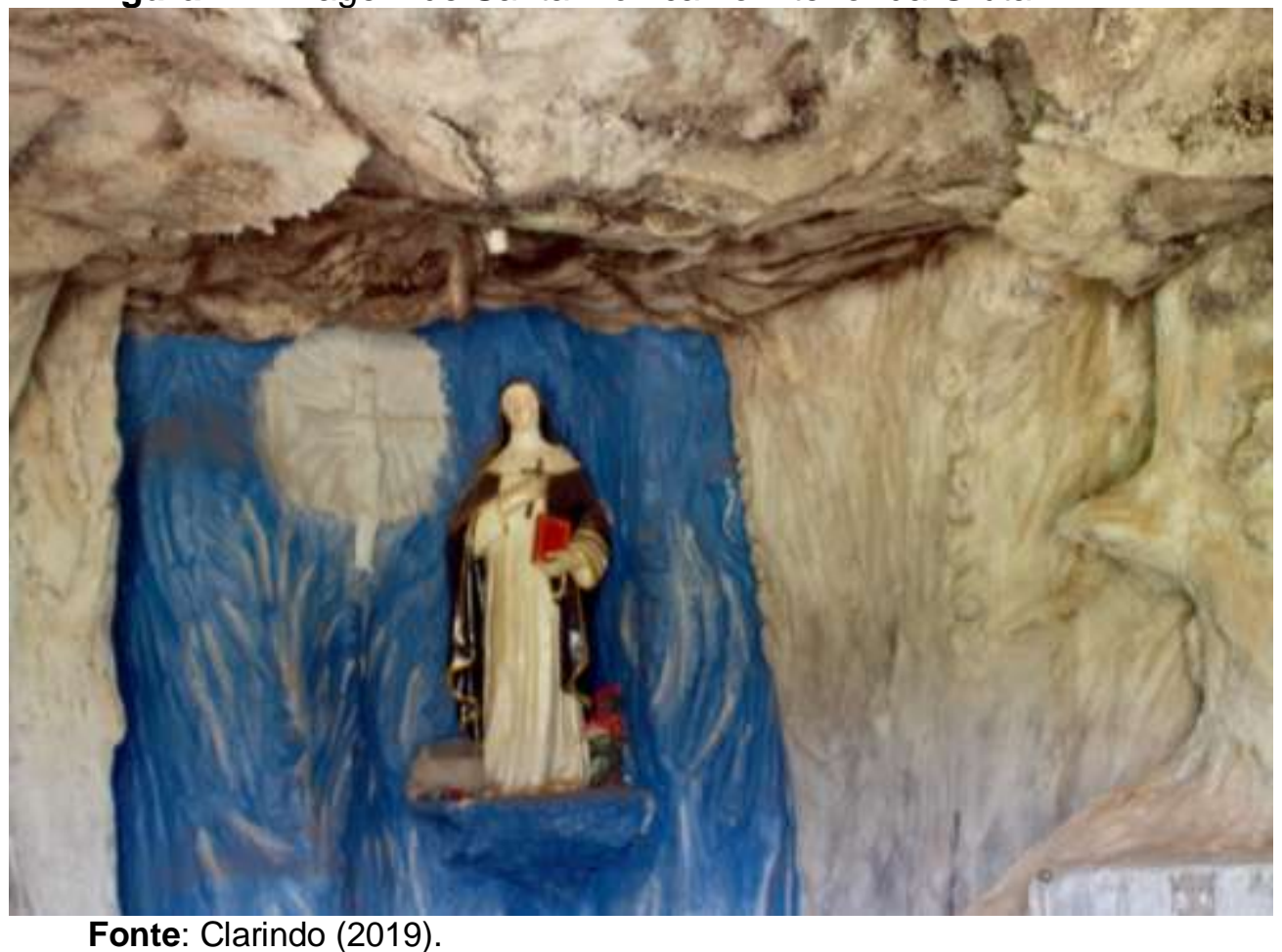

Inobstante, a cidade de Ponta Grossa conta com outra presentificação envolvendo uma nascente de água. O olho d'água São João Maria é também um dos marcadores territoriais da religiosidade popular local.

De acordo com Welter (2007), João Maria aparece na maior parte das investigações com sua vivência atrelada à Guerra do Contestado. Por outro lado, há inúmeras dissonâncias nas histórias envolvendo João Maria, e alguns autores retratam que existiram três homens reconhecidos pela sociedade da época com o nome do monge.

O primeiro surgiu em meados do século XIX, na década de 40 , pouco depois das revoltas liberais que sacudiram o Brasil e pouco antes do término da Guerra dos Farrapos. O segundo marcou sua presença nos anos próximos à abolição da escravidão e do advento da República; em meio à Revolução Federalista temos o seu primeiro registro concreto. Finalmente, José Maria, o terceiro monge, surgiu em 1912, quando a Primeira República incentivava largamente a imigração e a construção de estradas de ferro, com contratos altamente vantajosos para as construtoras (CARNEIRO JUNIOR, 2005, p. 18).

Welter (2007) apõe que há uma sobreposição identitária feita pela população sobre João Maria, tanto pelas questões de parentesco envolvendo estas pessoas com pela crença na reencarnação. É mais provável, porém, que o que fez fama pela região da Lapa e dos 
Campos Gerais era João Maria de Agostini (ou de Agostinho como ficou apelidado), que teria chegado da Itália em 1844 e circulado na região Sul e Sudeste do país, inclusive na região fronteiriça com outros países da América Latina.

O contexto social da época (final do século XIX e início do século $X X$ ), em que o interior era esquecido pelo poder público, favoreceu o fortalecimento de sua imagem na região. Welter (2007) acrescenta que a população sertaneja era, inclusive, carente no prospecto religioso, de modo que os padres da época dificilmente se deslocavam para o interior e quando o faziam posicionavam-se de maneira incompatível com a realidade local, sustentados pela ortodoxia da igreja e/ou outros interesses hegemônicos.

Deve-se considerar que havia naquele período um ideal amplo de exclusão de negros e índios, organizado num projeto de "civilização" coercitiva da população brasileira, envolvendo diferentes setores sociais: igreja, Estado e academia, dentre outros. Assim, por uma questão de identificação, monges como João Maria se sobressaem ao fornecer alento às populações esquecidas e menosprezadas.

João Maria, no entanto, não possuía significação somente para os mais pobres, sua presentificação se dava mesmo em meio às elites políticas e religiosas da época. São muitas as formas pelas quais a literatura se refere a ele: peregrino, curador, benzedor, rezador, ermitão, monge, profeta e messias, dentre outros. Efetivamente, João Maria andarilhava pelo interior realizando profecias, curando com ervas e águas bentas e orientando espiritualmente as pessoas desassistidas.

A imagem bondosa do monge é contrastada com inúmeras lendas de castigos por ele encomendados. Todavia, é neste cenário dúbio que se sustenta a imagem do Monge João Maria. "As curas são constantes em suas lendas. Teria curado adultos e crianças já à morte com infusões de uma planta chamada vassourinha e rezas. Em Mangueirinha e na Lapa, se contam casos de curas milagrosas de dores de dentes" (CARNEIRO JUNIOR, 2005, p. 22).

Além de Ponta Grossa, em outros municípios também existem olhos d'água atrelados à São João Maria. "Dizem que no local onde ele passava as noites, no dia seguinte formavase uma mina de água, dita por eles 'olho d'água', com água limpa e cristalina. E que tinha poder de curar" (CARNEIRO JUNIOR, 2005, p. 32).

É comum que nestas nascentes de água sejam construídas grutas ou outras edificações em memória de São João Maria, conforme figura 5. Atualmente, o monge possui ampla projeção nos estados do Paraná e Santa Catarina. Seja no meio rural ou urbano, seus feitos e histórias são presenças contumazes, sobretudo quando relacionadas com o fenômeno da medicina popular.

Além das visitas em busca de graça e proteção, o olho d'água São João Maria em Ponta Grossa é palco de batismos. Trata-se de uma característica da cultura da região, mas também é provável que isto aconteça em decorrência do fato de que a igreja católica 
impede que padrinhos não casados na igreja ou que não tenham os sacramentos da $1^{\text {a }}$ comunhão e crisma batizem uma criança. Sendo assim, algumas famílias optam por realizar o batismo em casa ou no olho d'água.

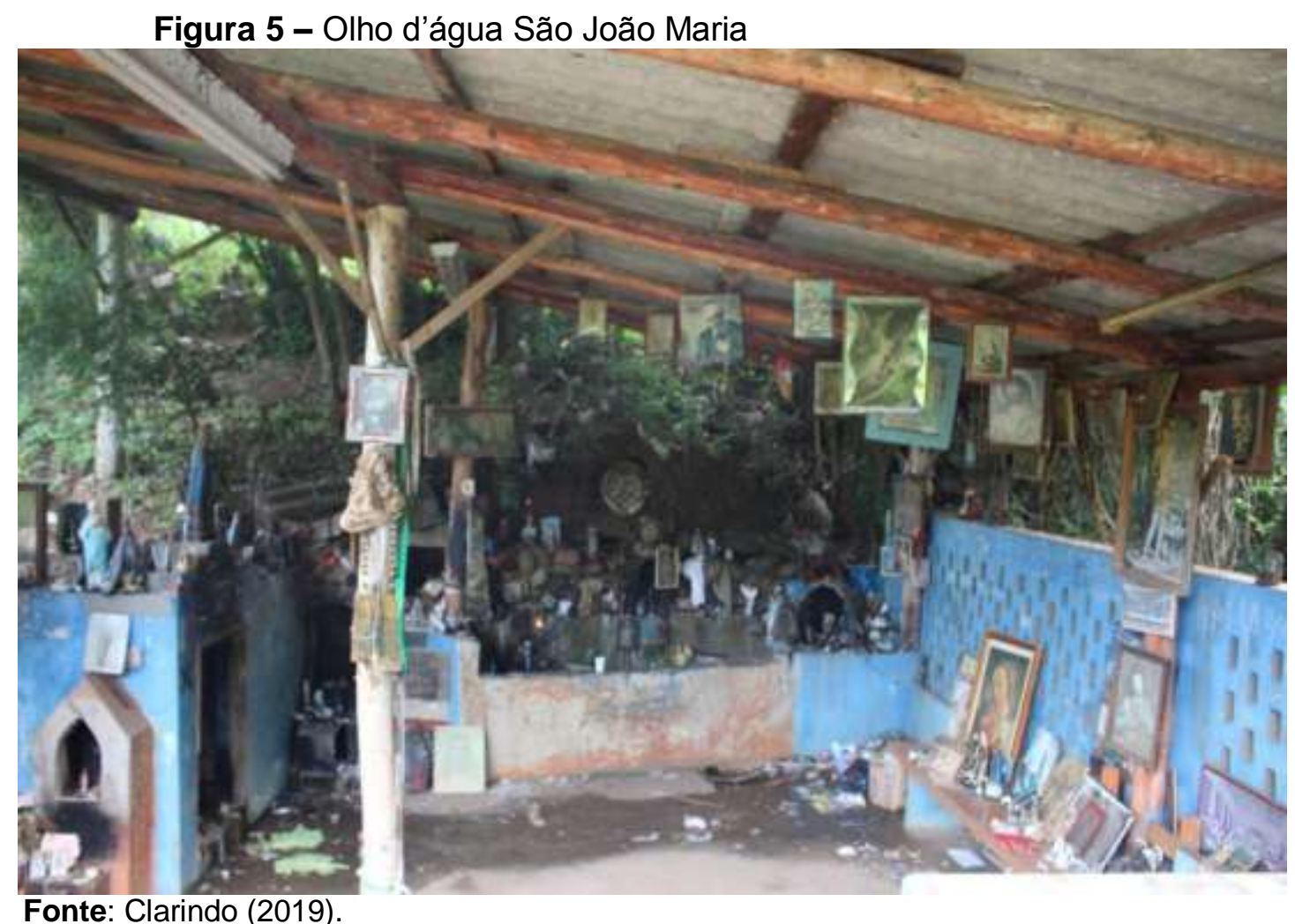

No local é comum a presença de imagens de santas(os) quebradas. Como não é recomendável jogar no lixo imagens que tenham sido despedaçadas acidentalmente, as pessoas as levam até o olho d'água, conforme figura 6 .

Pode-se observar no local que além das imagens de santas(os) católicas há também a presença de imagens atreladas à outras crenças (Pretos Velhos, Ciganas e Médiuns, dentre outras). Estas imagens ilustram a pluralidade que reveste a religiosidade popular. A fé em João Maria e em outras divindades permanece latente na cidade, haja vista que junto desta pluralidade religiosa popular há várias fotos de pessoas, cartas com pedidos/agradecimentos e velas espalhadas pelo local, que se renovam ao longo dos dias em reconhecimento pelas graças alcançadas e/ou novos pedidos. Atualmente não se recomenda o consumo da água da vertente por haver um esgoto clandestino desaguando próximo, outrossim o local tem sido alvo de vandalismos constantes.

A presença e persistência destes locais em meio ao espaço urbano moderno retrata com exatidão um outro percurso de fé. Não se trata de abdicar necessariamente dos valores e práticas arraigados às instituições, mas de outro caminhar espiritual/ritualístico, que se alterna entre complementariedade e exclusividade. 
Figura 6 - Imagens de santas quebradas no olho d'água São João Maria

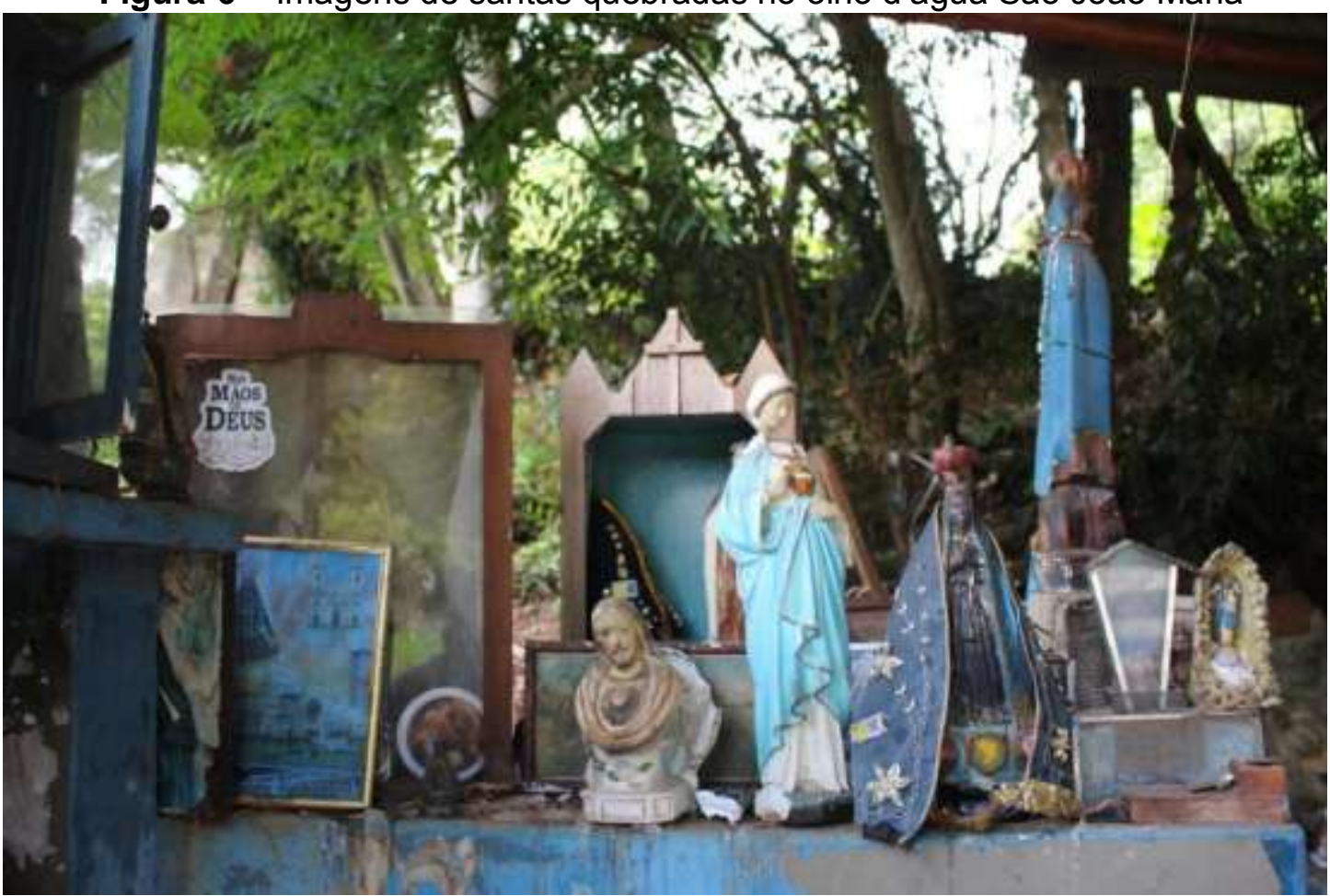

Fonte: Clarindo(2019).

\section{CONSIDERAÇÕES FINAIS}

A releitura espacial do urbano proposta neste artigo evidenciou que a cidade absolutamente não é uma única realidade social. Elegeram-se para ilustrar esta afirmação alguns marcadores territoriais que apontam outros valores religiosos e espirituais impregnados na vida urbana. Entre Santos canônicos, como Santa Mônica, e outros não reconhecidos institucionalmente, a sociedade organiza seu corpus de saberes e crenças.

A compreensão deste corpus é necessidade premente na compreensão das múltiplas espacialidades, já que o espaço urbano tomado por múltiplo atesta a presença de uma ancestralidade mítica, presente no inconsciente coletivo. Fala-se de uma abordagem desde as vivências espaciais organizadas por pessoas comuns, através de suas identidades, sentimentos, sensações, memórias etc.

Neste sentido, a espiritualidade, enquanto campo autônomo da religião e dimensão, afeta a cada ser humano e fornece subsídios para uma outra leitura espacial e também para a construção de uma nova agenda dentro da ciência geográfica. Medir silêncios e lidar com abstrações é parte do novo paradigma científico, cuja presença incontestável não deixa margem para que as discussões sejam negadas e/ou invisbilizadas.

Assente na perspectiva do Bem Viver (Buen Vivir), as múltiplas espacialidades inseridas no espaço urbano moderno das cidades ilustram a força de resistência 
social/cultural da sociedade frente aos processos totalizantes. Nestes marcadores territoriais ocorre também a reinterpretação de signos modernos, colocando em questionamento a modernidade e o crescimento infinito como únicos destinos do mundo. É, portanto, nestes interregnos espaciais que se dá uma singela, porém profunda ruptura com a lógica capitalista/colonial. Nestes há uma potente abertura para a reaproximação da sociedade com a natureza através do estímulo para a reflexão acerca do antagonismo - imaginário e/ou disciplinar - entre campo/cidade, mediante o resgate de geossímbolos rurais e da memória dos antepassados.

\section{REFERÊNCIAS}

ACOSTA, Alberto. O bem viver: uma oportunidade para imaginar outros mundos. São Paulo: Autonomia Literária/Elefante, 2016.

BOLLNOW, Otto. O homem e o espaço. Curitiba: UFPR, 2008.

BONNEMAISON, Joël. Viagem em torno do território. In: CORRÊA, Roberto Lobato; ROSENDAHL, Zeny. (orgs.). Geografia cultural: um século. Rio de Janeiro: EDUARJ, 2002. p. 83-131.

BOURDIEU, Pierre. Razões práticas: sobre a teoria da ação. Campinas: Papirus, 2007.

CARNEIRO JUNIOR, Renato Augusto. Lendas e contos populares do Paraná. Curitiba: Secretaria de Estado da Cultura, 2005.

CASSIRER, Ernst. A filosofia das formas simbólicas. São Paulo: Martins Fontes, 2001.

CLARINDO, Maximillian Ferreira. A Geografia da cura e do sagrado: a resistência das benzedeiras no espaço urbano de Ponta Grossa. 2019. Tese. (Doutorado em Geografia) Universidade Estadual de Ponta Grossa, Ponta Grossa, 2019.

COLUCCIO, Félix. Las devociones populares argentinas. Buenos Aires: Nuevo Siglo, 1995.

CORREA, Roberto Lobato. O espaço urbano. São Paulo: Ática, 2004.

DI MÉO, Guy. Introduction à la géographie sociale. Paris: Armand Colin, 2014.

ELIADE, Mircea. Tratado de historia de las religiones. Madrid: Cristiandad, 2000.

ESCOBAR, Arturo. Sentipensar com la tierra. Nuevas lecturas sobre desarrollo, território y diferencia. Medellín: Ediciones UNAULA, 2014.

FERNANDES, Josué Corrêa. Corina Portugal: história de sangue \& luz. Ponta Grossa: Gráfica Planeta, 1999.

FLORIANI, Nicolas et. al. Microterritorialidades rurais em um espaço urbano no sul do Brasil: imaginários geográficos e outros modos de habitar na cidade. In: LIMA, Rosirene Martins; SHIRAISHI NETO, Joaquim; SOUZA FILHO, Benedito. Dinâmicas territoriais e conflitos socioambientais. São Luís, Maranhão: UEMA, 2018. p. 61-87.

FORTUNA, Carlos. (Micro)territorialidades: metáfora dissidente do social. Terr@ Plural, Ponta Grossa, v. 6, n. 2, p. 199-214, jul./dez. 2012.

FOUCAULT, Michel. Vigiar e punir: nascimento da prisão. Petrópolis: Vozes, 1999.

GIDDENS, Anthony. Modernidade e identidade. Rio de Janeiro: Jorge Zahar, 2002.

GIL, Antônio Carlos. Métodos e técnicas de pesquisa social. São Paulo: Atlas, 2008. 
GUATTARI, Felix. Revolução molecular: pulsações políticas do desejo. São Paulo: Brasiliense, 1987.

JUNG, Carl Gustav. O homem e seus símbolos. 3. ed. Rio de Janeiro: HarperCollins, 2016.

JUNG, Carl Gustav. O inconsciente pessoal e o inconsciente coletivo. Rio de Janeiro: Vozes, 2000.

MATHIEU, Nicole. Le concept de mode d'habiter à l'épreuve du développement durable. Paris: l'Académie d'agriculture de France, 2010. Disponível em: https://halshs.archives-ouvertes.fr/halshs-00732262. Acesso em: 28 jul. 2020.

MAUÉS, Raymundo Heraldo. Um aspecto da diversidade cultural do caboclo amazônico: a religião. Estudos Avançados, São Paulo, v. 19, n. 53, p. 259-274, 2005. Disponível em: https://www.scielo.br/pdf/ea/v19n53/24092.pdf. Acesso em: 28 jul. 2020.

MELO, Mário Sérgio de; MORO, Rosemeri Segecin; GUIMARÃES, Gilson Burigo. Patrimônio natural dos campos gerais. Ponta Grossa: UEPG, 2007.

MONASTIRSKY, Leonel Brizolla. Ferrovia: patrimônio cultural. Estudo sobre a ferrovia brasileira a partir da região dos Campos Gerais (PR). 2006. Tese (Doutorado em Geografia) - Universidade Federal de Santa Catarina, Florianópolis, 2006.

PETRUSKI, Maura Regina. Eu oro, tu oras, eles oram para Corina Portugal. Revista Brasileira de História das Religiões, Maringá, ano 4, n. 12, jan. 2012. Disponível em: http://www.dhi.uem.br/gtreligiao/pdf11/07.pdf. Acesso em: 28 jul. 2020.

RAFFESTIN, Claude. De l'ideologie à l'utopie ou la pratique du géographe. Geographica Helvetica, Zurich, v. 41, n. 3, p. 133-136, 1986. Disponível em:

http://www.geogrhelv.net/41/126/1986/gh-41-126-1986.pdf. Acesso em: 28 jul. 2020.

SILVA, Adnilson de Almeida. Territorialidades e identidade dos coletivos Kawahib da terra indígena Uru-Eu-Wau-Wau em Rondônia: "Orevaki Are" (reencontro) dos "marcadores territoriais". 2010. Tese (Doutorado em Geografia) - Universidade Federal do Paraná, Curitiba, 2010.

SILVA, Gizele. 'Corina Portugal' acolhe mulheres vítimas de violência. Diário dos Campos, Ponta Grossa, 6 ago. 2016. Notícia. Disponível em:

https://www.diariodoscampos.com.br/noticia/corina-portugal-acolhe-mulheres-vitimas-deviolencia. Acesso em: 28 jul. 2020.

SIMMEL, Georg. A metrópole e a vida mental. In: VELHO, Otávio Guilherme (org.) 0 fenômeno urbano. Rio de Janeiro: Zahar Editores, 1973. p. 11-25.

SPIVAK, Gayatri Chakravorty. Pode o subalterno falar? Belo Horizonte: UFMG, 2010.

WELTER, Tânia. O profeta São João Maria continua encantando no meio do povo. 2007. Tese (Doutorado em Antropologia Social) - Universidade Federal de Santa Catarina, Florianópolis, 2007.

ZULIAN, Rosângela Wosiack. Entre o aggiornamento e a solidão: práticas discursivas de D. Antônio Mazzarotto, primeiro bispo diocesano de Ponta Grossa - PR (1930-1965). 2009. Tese. (Doutorado em História) - Universidade Federal de Santa Catarina, Florianópolis, 2009.

Recebido: junho de 2020. Aceito: agosto de 2020. 